\title{
O problema do emprego em Palmas-PR: uma proposta de rompimento do ciclo vicioso
}

\author{
Alexandre Luiz Schlemper \\ Instituto Federal do Paraná (Ifpr/Campus Palmas)
}

Recebido: 18/06/2015 Versão revisada (entregue): 27/08/2015 Aprovado: 31/08/2015

\begin{abstract}
Resumo
Neste estudo se apresenta uma breve análise sobre a condição de desenvolvimento do município de Palmas-PR a partir de um diagnóstico da dinâmica do emprego. Para tal, são levantados aspectos da distribuição do emprego por atividades econômicas, rotatividade e migração interna. A metodologia aplicada utilizou como fontes dados secundários de emprego junto ao CAGED e entrevistas. O diagnostico é de que existe um problema de alta rotatividade de emprego, fundamentalmente, na indústria madeireira de chapas de compensado, migrando a mão de obra, sazonalmente, para as atividades temporárias da colheita da maçã e da batata, mas, retornando, posteriormente, para a indústria. Este ciclo vicioso é avaliado pela teoria da causação circular cumulativa, de Gunnar Myrdal, a partir da qual também se apresentam sugestões para a sua quebra, de forma a convertê-lo em ciclo virtuoso. As propostas apresentadas fundamentam-se na oportunidade de construção de um planejamento participativo, conduzido pelo movimento da sociedade civil organizada, chamado Palmas Desenvolvida, e na atuação do Instituto Federal do Paraná em suas atividades de ensino, pesquisa e extensão, promovendo novas atividades econômicas propulsoras do desenvolvimento local.
\end{abstract}

Palavras-chave | Ciclo vicioso; ciclo virtuoso; desenvolvimento local; emprego; Palmas-PR.

Código JEL | J61; O15; R38.

\section{THE PROBLEM OF EMPLOYMENT IN PALMAS-PR: A PROPOSAL OF BREAKING THE VICIOUS CYCLE}

\begin{abstract}
The study presents a brief reflection on the development status in Palmas-Paraná State (Brazil), from a diagnosis of employment dynamics. For such aspects concerning the distribution of employment by economic activities, their turnover and internal migration are posed. The methodology used secondary data on employment with CAGED as a source, in addition to interview with the workers agency in Palmas. The diagnosis concludes that there is a problem of high turnover of jobs, mainly in the timber industry of plywood sheets, in which labor migrates seasonally to the temporary activities of apple and potato harvest, later returning to industry,
\end{abstract}


thus forming a vicious cycle. This cycle is evaluated by Gunnar Myrdal's theory of circular and cumulative causation, according to which, also are presented suggestions for breaching and converting it into a virtuous cycle. The proposals are based on the opportunity to build a participative planning led by the movement of the organized civil society called Palmas Developed and the performance of Parana Federal Institute in its teaching, research and extension, promoting new economic activities driving local development.

Keywords | Employment; local development; Palmas; vicious cycle; virtuous cycle.

JEL-Code | J61; O15; R38.

\section{EL PROBLEMA DEL EMPLEO EN PALMAS-PR: UNA PROPUESTA DE INTERRUPCIÓN DEL CICLO VICIOSO}

\section{Resumen}

El estudio presenta una breve reflexión sobre el estado de desarrollo de la ciudad de PalmasEstado de Paraná (Brasil) de un diagnóstico de la dinámica del empleo. Para tales aspectos son levantados datos de la distribución del empleo por actividades económicas, su volumen de negocio y la migración interna. La metodología utilizó como fuente, datos secundarios obtenidos en CAGED y una entrevista con el representante de la Agencia de los trabajadores de Palmas. El diagnóstico concluye que es un problema la elevada rotación de puestos de trabajo, principalmente en la industria de la madera de hojas de madera contrachapada, donde el trabajo migra estacionalmente a las actividades temporales de la manzana y la cosecha de papa, después de regresar a la industria, formando un círculo vicioso. Este ciclo se evalúa por la teoría de la causalidad circular y acumulativa de Gunnar Myrdal, la cual, también coloca sugerencias para su superación, convirtiéndola en un círculo virtuoso. Las propuestas se basan en la posibilidad de construir una planificación participativa impulsada por el movimiento de organizaciones de la sociedad civil, llamados Palmas Desarrollado y el desempeño del Instituto Federal de Paraná en su enseñanza, investigación y extensión, la estimulando nuevas actividades económicas que impulsan el desarrollo local.

Palabras-clave | Ciclo vicioso; ciclo virtuoso; desarrollo local; empleo; Palmas.

Código JEL | J61; O15; R38.

\section{Introdução}

O presente trabalho tem por objetivo realizar um diagnóstico da dinâmica do emprego na cidade de Palmas-PR, a fim de avaliar as condições de desenvolvimento local, detectando deficiências e propondo mudanças. Baseado na teoria do desenvolvimento local endógeno, que tem como elementos centrais os atores e as potencialidades locais, é realizado um diagnóstico econômico de Palmas, com ênfase na estrutura produtiva e suas principais atividades empregadoras, e a geração e movimentação do emprego dentro destas atividades.

Como procedimentos metodológicos para a consecução do objetivo, utilizaram-se dados de fonte secundária para caracterização do emprego em Palmas e sua 
dinâmica de movimentação. A análise é complementada com entrevista qualitativa junto a Agência do Trabalhador da cidade, com objetivo de contrastar os dados estatísticos e a percepção de um agente diretamente envolvido nessa dinâmica do emprego.

O trabalho esta estruturado em cinco partes, sendo esta introdução, a primeira. A segunda parte traz a breve revisão conceitual de crescimento econômico, desenvolvimento econômico e desenvolvimento local, afunilando o debate para o desenvolvimento endógeno, papel dos atores locais e o processo de empoderamento da comunidade local. A parte três procura caracterizar o município de Palmas, apresentando inicialmente informações gerais do município e a historia de sua formação econômica, e, posteriormente, realizando um diagnostico da condição do emprego e sua dinâmica. A parte quatro descreve o movimento da sociedade civil organizada intitulado "Palmas Desenvolvida", o qual procura articular, atualmente, a sociedade palmense em um processo participativo de planejamento. Ainda na parte quatro, avalia-se o diagnóstico realizado anteriormente à luz da teoria da causação circular cumulativa de Gunnar Myrdal e, também, apresentam-se propostas de criação na cidade de Palmas de atividades produtivas com potencial de geração de efeitos propulsores fortes, capazes de impulsionar o desenvolvimento da cidade. Por fim, a parte cinco apresenta as conclusões acerca do trabalho realizado.

\section{Procedimentos metodológicos}

A metodologia utilizada foi a pesquisa documental de fonte secundária, que segundo Marconi e Lakatos (2010), utiliza leis, documentos e informações estatísticas ainda não devidamente analisados, sendo, neste caso, informações oficiais provenientes de fontes estatísticas governamentais do Cadastro Geral de Empregados e Desempregados (CAGED) e do Instituto Brasileiro de Geografia e Estatística (IBGE). A análise das estatísticas de emprego concentrou-se em comparar os desligamentos e admissões em dois segmentos principais no CAGED, indústria de transformação (chapa de compensado) e setor agropecuário (atividades agrícola, da maçã e da batata), cruzando aquelas estatísticas com os dados de pedidos de seguro desemprego no período de um ano (agosto/2013 a julho/2014). Esta comparação possibilitou estabelecer uma correlação entre a mobilidade do emprego entre os setores e também a adesão ao benefício temporário do seguro desemprego, em um movimento cíclico anual. Com o objetivo de reforçar a análise quantitativa, apresentada pelos dados estatísticos, realizou-se também entrevista semiestruturada, de cunho qualitativo, com representante da Agência do Trabalhador da cidade de Palmas-PR. A opção pela entrevista deste ator deu-se por sua interlocução entre os setores patronais e os setores dos trabalhadores dos segmentos em estudo, possuindo, assim, uma ampla 
e importante visão sobre esta dinâmica do emprego na cidade. A análise da entrevista seguiu a técnica de análise de conteúdo de Bardin (1997), com as seguintes fases de procedimento: 1) Pré-análise, 2) Exploração do material e 3) Tratamento dos resultados, a inferência e a interpretação.

\section{O que é desenvolvimento local?}

Antes de tratarmos o conceito de desenvolvimento local, há a necessidade de abordarmos a diferenciação entre crescimento econômico e desenvolvimento econômico. Gremaud et al. (2002) define crescimento econômico como evolução de índices de produtividade em termos quantitativos, enquanto desenvolvimento econômico possui uma abrangência muito maior e está relacionado a condições gerais de qualidade de vida das pessoas daquela comunidade. Essa diferenciação também é tema da analogia de Boisier (2002) a partir de uma leitura histórica, apontando o surgimento do termo desenvolvimento no período pós-guerra, estando atrelado em um primeiro momento a índices econômicos isolados, principalmente o PIB e mais tarde o PIB per capita. Somente adiante, quando se admitem a intangibilidade e a subjetividade como elementos componentes do processo de desenvolvimento, é que áreas como saúde e educação passam a figurar em sua avaliação.

Os autores tradicionais do crescimento econômico centram suas teorias fortemente nos fatores de produção, capital e trabalho. Para Harrod (1979), o crescimento econômico balanceado e equilibrado não ocorre de forma natural, ele depende da quantidade do capital e seu investimento, que leva ao acúmulo deste e consequente crescimento econômico. Já Kaldor (1979) propõe a condição de crescimento econômico equilibrado a partir de três fatores: 1) intervenção do Estado; 2) grandes empresas monopolistas; e 3) os sindicatos. Ainda com ênfase no capital e trabalho, Solow (1979) distingue o comportamento dos dois fatores, argumentando que a força de trabalho possui crescimento natural e que é necessário dotá-la de uma certa parcela de capital, para que o crescimento econômico se consolide. Este capital deverá ser oriundo das evoluções tecnológicas e resultar em poupança.

Mais contemporaneamente, Schumpeter (1982) apresenta sua teoria dos ciclos econômicos, afirmando que o crescimento econômico evolui até determinado estágio, quando reduz o crescimento e pode entrar em estagnação. Esta condição só é então quebrada pelo processo de inovação por intermédio de empresários empreendedores, trazendo uma nova dinâmica à economia, auferindo lucros acima dos padrões vigentes e reiniciando o ciclo de crescimento.

Partindo então da premissa segundo a qual desenvolvimento econômico engloba fatores econômicos quantitativos, como capital e trabalho, mas também e 
principalmente a promoção da qualidade de vida da população, este desenvolvimento pode partir de uma iniciativa externa, "de fora para dentro" da região, ou interna, "de dentro para fora" da região, sendo este último também chamado de desenvolvimento endógeno, e que tem ganho grande aceitação como estratégia de desenvolvimento local entre pesquisadores da área. Para Amaral Filho (2001), o desenvolvimento endógeno representa o crescimento econômico em continua ampliação da capacidade de agregação de valor sobre a produção, absorvendo e retendo o excedente econômico na própria economia local, conseguindo ainda a atração de excedente de outras regiões. Nesta proposta de desenvolvimento endógeno, os atores locais ganham expressiva relevância, conforme Martinelli e Joyal (2004, p. 11):

O novo paradigma de desenvolvimento regional endógeno está no fato de que o modelo de desenvolvimento possa ser estruturado a partir dos próprios atores locais e não mais pelo planejamento centralizado. $\mathrm{O}$ modelo pode ser definido como um desenvolvimento realizado de baixo para cima, ou seja, partindo das potencialidades socioeconômicas originais do próprio local em vez de um modelo de desenvolvimento imposto de cima para baixo pelo poder central do estado.

Oliveira e Ferrera de Lima (2012) reforçam a importância dos atores locais no processo de desenvolvimento endógeno, enquanto personagens referenciais; no entanto, chamam a atenção de que estes devem estar em constante diálogo externo no sentido de provocar e mobilizar o dinamismo da região. Esta afirmação fortalece o entendimento de que o estudo das condições locais como meio de detectar as potencialidades, vocações e necessidades é pertinente como meio de canalizar os esforços e investimentos em áreas estratégicas para o desenvolvimento local e regional. É importante também esclarecer que abordar-se o desenvolvimento sob este prisma de "baixo para cima" não significa afirmar que haverá um isolamento ou enclausuramento da região em relação às instâncias macro regionais, nacionais e globais, mas, sim, a maior participação de todos os sujeitos envolvidos em ações articuladas que possam trazer o desenvolvimento regional.

Segundo Boisier (2002), todo o esforço de centralização das potencialidades locais poderá acontecer no sentido de resposta às realidades e necessidades globais:

Todo proceso de desarrollo endógeno se vincula al desarrollo local de una manera asimétrica: el desarrollo local es siempre un desarrollo endógeno, pero este puede encontrarse en escalas supra locales, como la escala regional por ejemplo (BOISIER, 2002, p. 14). 
Tendo os atores locais papel fundamental no processo de construção de um projeto de desenvolvimento endógeno, cabe definir os instrumentos de sua participação. Para Franco (1999), este instrumento é a política, uma vez que a capacitação em termos de conhecimento e a educação como emancipadora do cidadão são condições importantes, mas não suficientes para promover a efetiva participação comunitária, que viria através do exercício político do debate coletivo. Para Vitte (2006), o poder local é o poder de forças, em torno das quais se processam alianças e confrontos entre atores sociais em um espaço delimitado. Esse processo de empoderamento comunitário é essencial para construção do desenvolvimento local, através da identificação, valorização e utilização das capacidades de seus integrantes, ao invés de simplesmente apontar suas necessidades (OLIVEIRA, 2006).

Haddad (2009) apresenta um modelo com etapas do processo de desenvolvimento endógeno a partir dos atores locais:

Figura 1 Etapas do processo de desenvolvimento endógeno

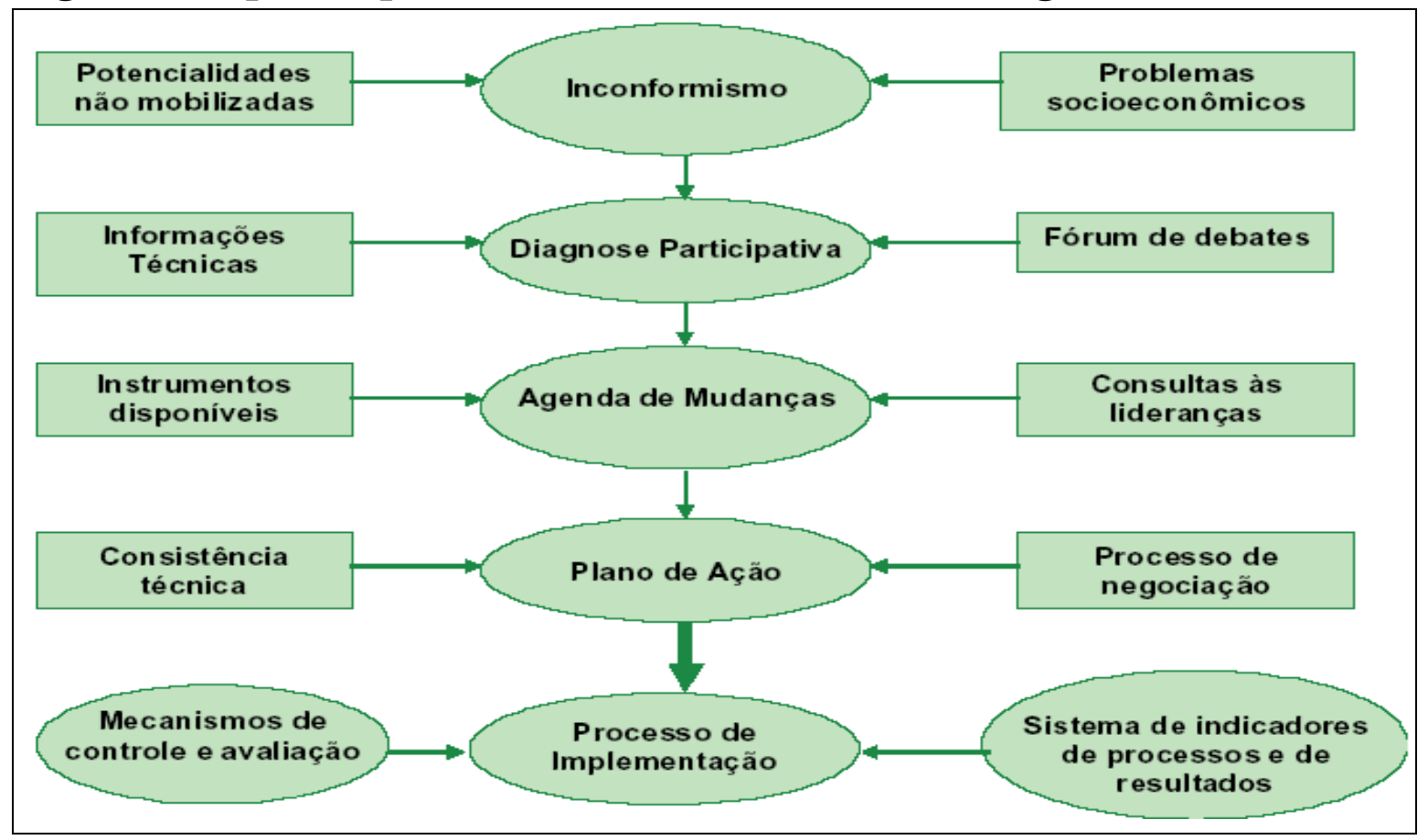

Fonte: Haddad (2009).

Pela sequência proposta, o processo de desenvolvimento endógeno é disparado pelo inconformismo da comunidade local com sua condição, normalmente diante da passividade do poder público local. O passo seguinte é de diagnóstico, procurando compreender as causas que levaram a tal condição. A terceira etapa surge a partir do diagnóstico e procura elaborar um planejamento de ações que promovam a alteração da condição local. A quarta etapa transforma o 
planejamento em plano de ações específicas com metas e prazos e a delegação de funções aos executores das ações. Por fim, o planejamento é levado a cabo, através da execução das ações que são monitoradas para verificação dos resultados.

Desta forma, o desenvolvimento endógeno e seus atores passam a representar uma das principais estratégias para o desenvolvimento local. Trata-se de um contexto no qual o território se transforma em nova forma de analisar os problemas do desenvolvimento econômico e da eficiência das atividades produtivas (FERRERA DE LIMA, 2012).

A discussão trazida até o momento sobre a transição do conceito de desenvolvimento, inicialmente centrado em elementos econômicos e posteriormente agregando fatores sociais, não é recente. Myrdal (1959, p. 31) já alertava que a teoria econômica tradicional não era suficiente para explicar as questões do desenvolvimento:

Cualquier estudio realista del subdesarrollo y del desarrollo de un país, o de una región de un país, bastante lejos de las fronteras de la teoría económica tradicional. Esto es necesariamente así porque el estudio tiene que ver con todos los llamados "factores no económicos" que los economistas clásicos agruparon bajo conceptos como la "calidad de los factores de producción" y la "eficiencia de la producción”, y que por lo general excluyeron de su análisis.

A admissão de fatores não econômicos auxiliou Myrdal (1959) a formular sua teoria da causação circular cumulativa no processo de desenvolvimento e subdesenvolvimento, na qual afirma que tanto o desenvolvimento quanto o subdesenvolvimento são a própria causa e consequência em si, reproduzindo-se continuamente em um ciclo vicioso de subdesenvolvimento ou circulo virtuoso de desenvolvimento. Para explicitar sua teoria, Myrdal produz um ensaio sobre uma comunidade negra estadunidense da década de 50, que enfrenta um ciclo vicioso em sua baixa qualidade de vida, sendo que os brancos a descriminam justamente por esta condição social e cultural, enquanto a comunidade não consegue sair de tal condição, exatamente pela discriminação exercida pelos brancos que não thes proporcionam oportunidades, fechando assim o ciclo vicioso.

Trazendo para o campo do desenvolvimento, Myrdal (1959) afirma que os causadores do ciclo vicioso do subdesenvolvimento são os efeitos retardadores gerados por atividades econômicas frágeis e estagnadas e que este ciclo só poderá ser rompido por meio de efeitos propulsores fortes, capazes de estimular novas atividades econômicas ou retomar as estagnadas, convertendo o ciclo em virtuoso de desenvolvimento. Neste sentido, duas estratégias principais são apontadas pelo autor: a primeira, através de planejamento articulado de politicas públicas que 
possam criar um ambiente atrativo para as atividades econômicas impulsionadoras e a segunda através da pesquisa e geração de conhecimento, capaz de prospectar, a partir das potencialidades locais, novas atividades econômicas com efeitos propulsores fortes.

Assim, o desenvolvimento local surge como proposta de melhoria da condição de vida das pessoas a partir de seu próprio território, através do empoderamento e participação dos atores locais no planejamento e na execução de um projeto de desenvolvimento que privilegie as potencialidades e capacidades locais.

\section{Município de Palmas-PR}

A instalação do município de Palmas, no estado do Paraná, foi realizada no ano de 1879, pela Lei Estadual no 233, de 18 de dezembro de 1896 (IBGE, 2014). Localiza-se nos chamados "Campos de Palmas", região Sudoeste do Paraná. Sua estruturação econômica inicia em meados da década de 1930, a partir dos "tropeiros", personagens que tiveram importante participação no processo de estabelecimento das primeiras atividades econômicas fixas. Estes, ao contrário dos exploradores Bandeirantes e das expedições Jesuítas, que apenas se utilizavam de atividades extrativistas, passaram a fomentar a fixação das primeiras casas de comércio e o início de atividades agropecuárias, que serviriam como suporte a suas passagens futuras pela região (KRÜGER, 2002).

A partir de então, Palmas e região passavam a configurar oficialmente no mapa econômico e produtivo do Paraná. Desse período em diante, até os dias atuais, algumas atividades econômicas ganharam destaque, como a pecuária, a fruticultura e, principalmente, a indústria madeireira, que passa a ser a principal empregadora. Essa indústria, no entanto, historicamente voltada ao mercado internacional de commoditties de chapas de compensado, tem se mostrado vulnerável a oscilações econômicas internacionais e a variações cambiais, gerando reflexos diretos no comportamento do emprego na cidade de Palmas, como se observa na Tabela 1:

Tabela 1 Relação entre cotação do dólar e comportamento do emprego em Palmas-PR

\begin{tabular}{llllllllllllll}
\hline & 2002 & 2003 & 2004 & 2005 & 2006 & 2007 & 2008 & 2009 & 2010 & 2011 & 2012 & 2013 \\
\hline Taxa/Dólar & 2,872 & 3,038 & 2,924 & 2,432 & 2,172 & 1,945 & 1,829 & 1,992 & 1,754 & 1,67 & 1,951 & 2,155 \\
Emprego & 1.353 & 1.377 & 382 & 290 & -771 & 131 & -140 & 112 & 243 & 198 & 716 & 189 \\
\hline
\end{tabular}

Fonte: Bacen (2014) e Caged (2014). 
Percebe-se no período observado uma relação entre a taxa cambial do dólar e a variação negativa do emprego no município de Palmas. Conforme a taxa do dólar cai a partir de 2003, as empresas de compensado perdem competitividade internacional, refletindo diretamente no comportamento do emprego, o que demonstra a dependência desta atividade econômica na estrutura de emprego ao longo destes anos no município de Palmas.

Esta variabilidade, com períodos de alta demanda das indústrias de compensado e posterior baixa, produziu um fenômeno de forte migração populacional à cidade no inicio da década de 2000, em função da oferta do emprego. Esta nova camada populacional, no entanto, permaneceu na cidade mesmo com o declínio da indústria madeireira, e, não havendo oportunidade de recolocação profissional, buscou alternativas informais de subsistência ou os benefícios dos programas sociais do Estado.

A partir desta dinâmica do emprego em Palmas procurou-se investigar mais especificamente esta dependência da indústria madeireira, realizando-se um diagnostico de sua movimentação e o status desta atividade econômica enquanto estagnada ou propulsora, dentro da teoria de causação circular cumulativa de Myrdal.

Segundo IPARDES (2014), Palmas possui atualmente a população economicamente ativa de 19.666 pessoas, das quais 18.717 estão ocupadas, indicando que o índice de desemprego não é alto. A partir disso, procurou-se avaliar a condição dessa ocupação de emprego, em que a distribuição de pessoas pelas principais atividades econômicas está assim colocada: 18\% na indústria de transformação (majoritariamente a indústria madeireira do compensado), 16\% no comércio, $14 \%$ na agricultura e pecuária, $8 \%$ na construção, $7 \%$ em serviços domésticos, $6 \%$ em educação, $4 \%$ transporte, $4 \%$ administração publica e as demais atividades representam menos de $3 \%$.

Duas das principais atividades econômicas, indústria de transformação e agropecuária, apresentam uma condição especial de sazonalidade e migração, conforme pode ser observado no Gráfico 1 (a seguir). 
Gráfico 1 Admissões, desligamentos e seguro desemprego em Palmas-PR, agosto/2013 a julho/2014)

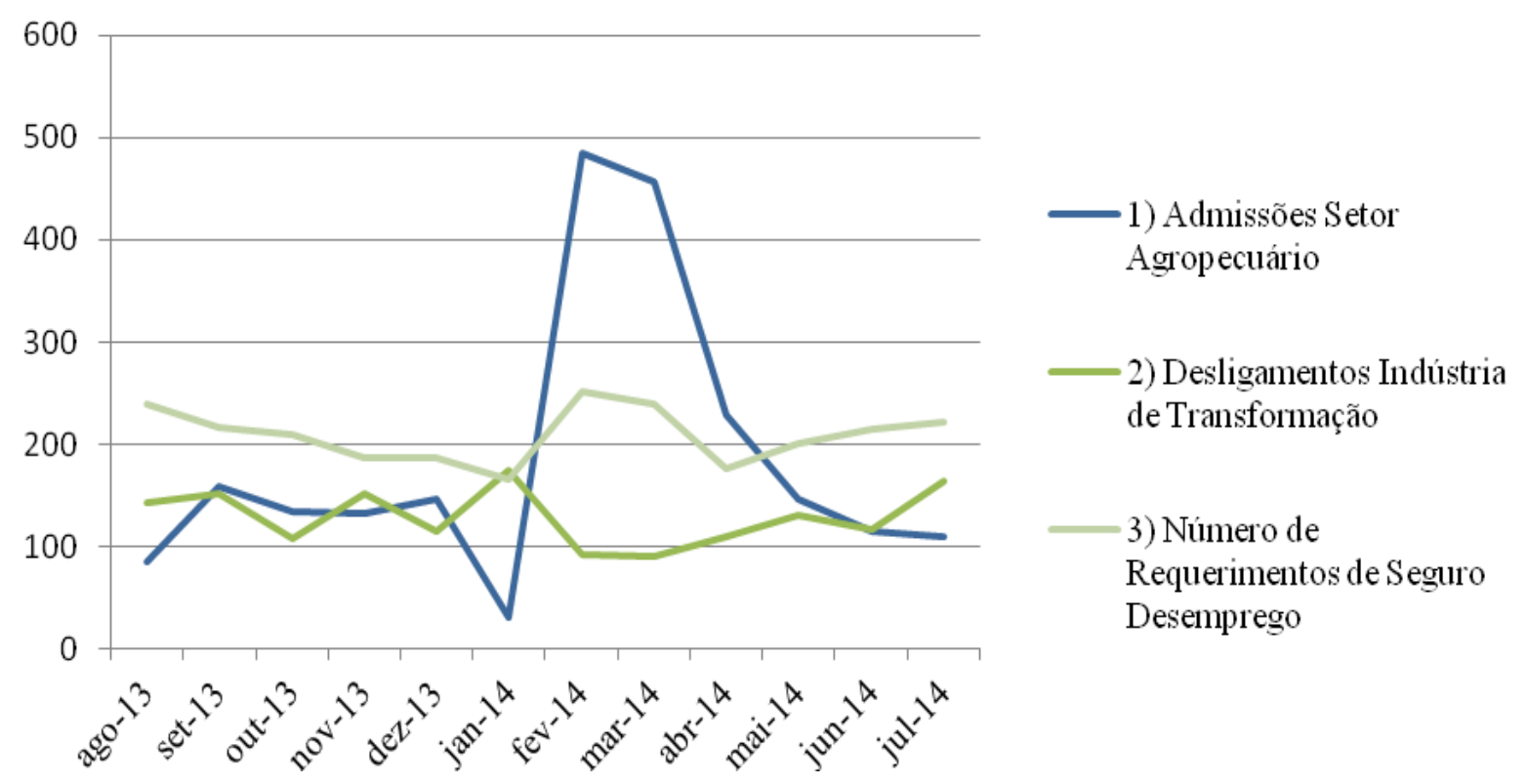

Fonte: Caged (2014).

Palmas possui duas importantes atividades agrícolas, a cultura da batata e a da maçã, que exigem uso intensivo de mão de obra temporária no período de colheita, o que tem ocasionado um deslocamento de mão de obra entre setores. $\mathrm{O}$ Gráfico 1 demonstra que no mês de janeiro há um pico de desligamentos na indústria de transformação, a qual ingressa em fevereiro no setor agropecuário, exatamente no período de colheita da maçã e da batata, que dura até maio, quando encerra-se o ciclo. Observa-se, também, que exatamente em fevereiro ocorre o pico de requerimentos de seguro desemprego, muito provavelmente dos trabalhadores que saíram da indústria e vão atuar informalmente na colheita da batata e da maçã. Em maio e junho, com o término da colheita e dos benefícios de seguro desemprego, a mão de obra desloca-se novamente para indústria até janeiro, reiniciando o ciclo.

Essa rotatividade de mão de obra é confirmada ainda pelos dados gerais de admissões e desligamentos ao longo dos anos, comprovando que o ciclo se repete anualmente, conforme demonstra a Tabela 2: 
Tabela 2 Variação do emprego em Palmas-PR

\begin{tabular}{lcccc}
\hline & $\mathbf{2 0 1 0}$ & $\mathbf{2 0 1 1}$ & $\mathbf{2 0 1 2}$ & $\mathbf{2 0 1 3}$ \\
\hline Admissões & 4.468 & 4.728 & 5.797 & 5.810 \\
Desligamentos & 4.247 & 4.690 & 5.091 & 5.713 \\
Saldo & 221 & 38 & 706 & 97 \\
Número de benefícios & 2.342 & 2.402 & 2.183 & 2.521 \\
\hline
\end{tabular}

Fonte: Caged (2014) e Agência dos Trabalhadores/SETS de Palmas (2014).

Nota-se na Tabela 2 que as admissões e demissões ocorrem praticamente na mesma proporção, sem produzir saldos significativos de emprego, e que, se considerada a população ocupada de 18.717 pela média de admissões e demissões, tem-se um índice de rotatividade de aproximadamente 25\%, com trabalhadores que saem da indústria e dividem-se entre o beneficio do seguro desemprego e a colheita da batata e da maçã, ou ainda ambos.

A Figura 2 resume o diagnóstico relativo à condição de emprego em Palmas e sua dinâmica de deslocamento sazonal

Figura 2 Deslocamento sazonal da mão de obra em Palmas-PR

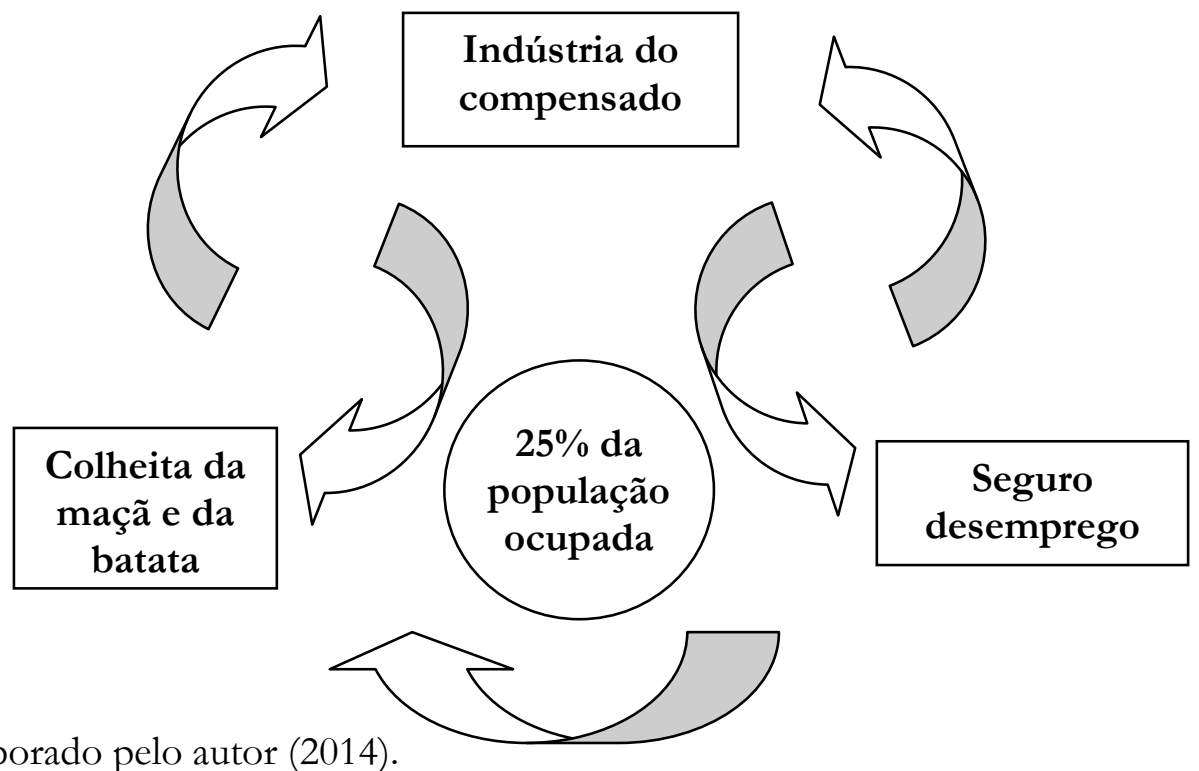

Fonte: Elaborado pelo autor (2014).

A Figura 2 ilustra os dados apresentados no Gráfico 1 e na Tabela 2, demonstrando a dinâmica de movimentação sazonal do emprego em Palmas. 
Anualmente, $25 \%$ da população economicamente ocupada deixa a indústria, especialmente a do compensado, e dirige-se para as atividades temporárias de colheita da maçã e da batata ou para requerer o beneficio de seguro desemprego. Ambas as situações, tanto das colheitas como do seguro desemprego, tem duração média de quatro meses, quando esta massa de trabalhadores retorna sistematicamente à indústria. A indústria, com defasagem de mão de obra e sem opções, acaba por recontratar estes trabalhadores, mesmo sabendo que o fenômeno se repetirá no ano seguinte.

No entanto, as recontratações ocorrem pelo piso salarial mínimo e nenhum investimento em qualificação ou de incentivo a esta mão de obra é realizado, sob a alegação de falta de cultura profissional e de comprometimento. Da parte dos trabalhadores, a justificativa é de que a baixa remuneração e a falta de plano de carreira acabam desestimulando sua permanência, fazendo-os migrar em busca de maiores rendimentos.

Essa condição pode ser diretamente relacionada à teoria do ciclo vicioso de Myrdal. Assim como o exemplo que o autor utiliza da comunidade negra estadunidense e da comunidade de brancos, em que ambas acabam agindo no sentido de perpetuar sua situação, no caso apresentado do emprego em Palmas, tanto o comportamento da indústria como dos trabalhadores fazem com que o ciclo vicioso de baixa qualificação profissional, baixa renda e falta de fidelidade profissional se auto reproduza continuamente. Para romper este ciclo, uma das duas partes precisaria mudar seu comportamento. Neste caso, acreditamos que deveria partir da indústria, fornecendo estímulos e uma perspectiva de longo prazo aos trabalhadores, de tal forma que não fossem seduzidos pelas oportunidades de maior renda das atividades temporárias.

A Agência dos Trabalhadores de Palmas poderia conduzir o processo de conversação entre os Sindicatos dos trabalhadores e patronal da madeira, e também representantes das empresas empregadoras, bem como os produtores da maçã e da batata, procurando aproximar as necessidades das partes. Para a empresa madeireira a rotatividade é negativa, seja pelos custos de demissão e admissão, seja pela inconsistência de oferta de mão de obra. Para o trabalhador, a migração também é negativa, especialmente pela incerteza de renda a médio e a longo prazo.

Assim, se a indústria madeireira ofertasse um plano de desenvolvimento profissional de médio e longo prazo, poderia estimular a permanência dos trabalhadores, e a redução de custos de demissão e admissão poderiam ser investidos em melhor remuneração dos trabalhadores, desestimulando a rotatividade. Para os produtores da batata e da maçã, a mão de obra temporária também não é estratégica, seja pelo custo de recrutamento ou pela variabilidade da oferta de mão de obra. Neste caso, entendemos que duas situações poderiam ser vislumbradas: a mecanização do trabalho, substituindo a mão de obra braçal por 
equipamentos de colheita automática, ou a transformação da mão de obra temporária em permanente, através da verticalização para cima, de processos de industrialização dos produtos, conseguindo alocar e gerenciar a mão de obra ao longo de todo o ano.

Estas proposições tratam especificamente da questão da migração de mão de obra entre a indústria madeireira e as colheitas temporárias da maçã e da batata. Mas a questão do desenvolvimento local de Palmas é mais complexa e abrangente e envolve, além de outras atividades econômicas, o processo de planejamento articulado proposto por Myrdal, temáticas a serem abordadas na sequencia deste trabalho.

\section{Movimento "Palmas Desenvolvida"}

Em abril de 2014 inicia na cidade de Palmas um movimento da sociedade civil organizada intitulado "Palmas Desenvolvida". Este movimento surge a partir de algumas lideranças locais, inconformadas com a atual condição de desenvolvimento da cidade e pela falta de perspectiva de mudança, aliada a passividade histórica do poder publico local. O objetivo do movimento é reunir representantes de todas as entidades da sociedade civil organizada de Palmas em um espaço permanente de debate, que, de forma articulada, possam pensar, planejar e construir seu próprio desenvolvimento sustentado.

A partir da sensibilização inicial, definiu-se uma agenda de reuniões nas quais podem-se construir coletivamente alguns elementos balizadores do movimento:

- Proposta: formação de um grupo permanente de debate, de planejamento e de ação para questões que promovam o desenvolvimento e a geração de emprego e renda no município de Palmas; o grupo não irá competir, nem rivalizar com nenhuma outra entidade, nem com os poderes públicos, mas pretende se somar a todas em vista do alcance de seus objetivos.

- Objetivo: construir uma Palmas desenvolvida com qualidade de vida para a população atual e para as futuras gerações.

- Missão: a partir da união da comunidade e suas lideranças, transcendendo partidarismo ou interesse de grupos, levar Palmas a pensar, planejar e construir seu próprio desenvolvimento sustentável, possibilitando sua população a viver com qualidade de vida.

Após a definição destes elementos norteadores do funcionamento do grupo, as próximas reuniões centraram-se no processo de diagnóstico e proposição de ações para o desenvolvimento de Palmas, das quais foram elencadas as seguintes ações estratégicas, por ordem de prioridades:

1. Buscar pacto pela representatividade política; 
2. Formação e capacitação profissional;

3. Apoiar e aproximar IFPR (Instituto Federal do Paraná) e comunidade local;

4. Criação do novo parque industrial e incubadora;

5. Ações institucionais de marketing para resgate da autoestima palmense;

6. Criação de um conselho de desenvolvimento econômico independente;

7. Levantar, revisar e divulgar leis de incentivo fiscal;

8. Fomento a atividades econômicas rurais;

9. Ampliar o conhecimento e participação em conselhos municipais;

10. Apoio ao associativismo e cooperativismo.

A primeira ação, por ocasião das eleições de outubro de 2014, já foi realizada, através da criação de um instrumento de comprometimento entre os candidatos a deputado estadual, deputado federal e governador do estado do Paraná para com as demandas locais. Este instrumento, a "Carta de Palmas", trouxe as principais reinvindicações da comunidade, bem como exigia do candidato que a assinasse, representatividade ativa da cidade de Palmas em sua respectiva instancia politica. Em troca, o movimento Palmas Desenvolvida comprometia-se a realizar uma campanha de conscientização do voto em candidatos que tivessem assinado a carta.

Atualmente, o estágio de trabalho no movimento dividiu as demais ações estratégicas em grupos de trabalho, responsáveis pela elaboração dos respectivos planos de ação, que serão submetidos à aprovação do grupo geral antes do encaminhamento da implementação. Na sequência do trabalho, o movimento Palmas Desenvolvida será abordado quanto a seu papel no processo de desenvolvimento endógeno de Palmas, a partir da teoria de Myrdal.

\section{Como romper o "ciclo vicioso" do emprego em Palmas}

A teoria trazida por Myrdal (1959) sobre a causação circular cumulativa sustenta que a pobreza e o subdesenvolvimento são a sua própria causa e consequência, ou seja, elas se reproduzem sistematicamente em um circulo vicioso. $\mathrm{E}$ isto ocorre fundamentalmente em função de efeitos propulsores fracos daquela região, causando um impacto regressivo no desenvolvimento. Para Myrdal, a forma de quebrar este ciclo vicioso poderá ocorrer por meio de duas ações principais: primeiramente, através de uma política de desenvolvimento planejada, e em seguida, com o uso do conhecimento já existente e produção de pesquisas que detectem potencialidades e as promovam como efeitos propulsores fortes. 
Para o caso do emprego de Palmas, conforme Figura 2, elaborou-se uma relação com a teoria da causação circular cumulativa de Myrdal, porque o efeito propulsor da indústria madeireira do compensado é fraco, devido sua volatilidade causada pela dependência das condições cambiais, impedindo um planejamento de longo prazo mais consistente por parte das empresas, o que compromete sua competitividade. Esta condição, somada as atividades primárias, também de baixa propulsão, da batata e da maçã, que atualmente não industrializam seus produtos, produzem um efeito de migração interna de $25 \%$ da mão de obra entre as três atividades, constituindo o ciclo vicioso do emprego em Palmas. Para redução desta rotatividade interna já foram apresentadas, no tópico 3, propostas tanto para a indústria, quanto para os produtores de maçã e batata. No entanto, o rompimento do ciclo vicioso do emprego em Palmas vai além da redução desta rotatividade interna.

Para transformação deste ciclo vicioso em circulo virtuoso, através da promoção de efeitos propulsores fortes, entendemos que duas situações se apresentam como oportunidades de realização deste processo, seguindo os apontamentos de Myrdal: i) o movimento Palmas Desenvolvida, enquanto movimento da sociedade civil organizada no processo de planejamento articulado, representando a ação de planejamento e construção de políticas públicas proposta por Myrdal, e ii) a presença do IFPR (Instituto Federal do Paraná) nas atividades de ensino, pesquisa e extensão, representando a ação de produção de conhecimento, através das pesquisas aplicadas às potencialidades locais, também proposta por Myrdal.

O movimento Palmas Desenvolvida, lido pelo modelo de desenvolvimento endógeno de Haddad (2009), conforme Figura 1, já ultrapassou os primeiro e segundo estágios, de inconformismo, sensibilização e diagnóstico, e ingressa nas fases seguintes de planejamento macro e planos de ação. Salientamos que o processo de diagnóstico deve ser continuo e amplamente participativo, pois o mapeamento das atividades propulsoras, baseadas nas potencialidades locais, é fundamental para que o planejamento e os planos de ação possam efetivá-las e impulsioná-las.

Este movimento da sociedade civil organizada pode representar, conforme salientam Martinelli e Joyal (2004) e Ferrera de Lima (2011), justamente a ação de protagonismo dos atores locais no processo de desenvolvimento na comunidade de Palmas, sendo efetivado, segundo Vitte (2006) e Oliveira (2006), pelo processo de participação e empoderamento que representa a estruturação e organização do Palmas Desenvolvida.

Em estudo de Denuzi e Ferrera de Lima (2013), que compara os processos de desenvolvimento das cidades de Assis Chateaubriand e Palotina, na região Oeste do Paraná, observou-se que o desempenho mais dinâmico de Palotina deveu-se principalmente a capacidade de articulação e conectividade entre organizações e o poder público, criando um ambiente de inovação e empreendedorismo, fazendo 
com que as organizações econômicas se sobressaíssem às politicas. Esta experiência pode servir de referência ao movimento Palmas Desenvolvida no sentido de efetivar algumas de suas proposições, como, por exemplo, a consolidação no município de um conselho econômico independente e atuante que ofereça ao poder executivo propostas e projetos de promoção do desenvolvimento.

Quanto à atuação do IFPR, segundo os documentos institucionais, existe um direcionamento enfático de atuação junto aos arranjos produtivos locais, que, no entanto, é prejudicado pela localização do Campus Palmas (SCHLEMPER, 2013). Para o autor, dos quatro APLs atuais da região Sudoeste do Paraná (Alumínio e Utensílios Domésticos, Confecções, Móveis e Software), apenas o de Alumínio e Utensílios Domésticos mantém empresas associadas na cidade de Palmas, com o agravante de que os outros três estão localizados a um distancia média de 200 quilômetros do Campus Palmas, o que torna quase impeditiva a atuação na modalidade de ensino, especialmente de nível técnico, fornecendo mão de obra qualificada a estes APLs. Esta situação, que no primeiro momento parece limitadora, pode, no entanto, converter-se em oportunidade, no sentido de que, de certa forma, "descompromissa" o IFPR dos APLs atuais, com exceção de alumínio e utensílios domésticos, pelo menos na modalidade ensino, e flexibiliza sua atuação ao fomento de novas atividades locais. Este fomento deverá ocorrer nas suas três modalidades de atuação: na pesquisa, prospectando oportunidades locais e desenvolvendo soluções aos empreendedores; na extensão, através da aplicabilidade das pesquisas e, principalmente, promovendo a governança e articulação das novas atividades econômicas a serem estimuladas; e do ensino, na formação de mão de obra especializada, nos níveis operacional, técnico e estratégico.

Partindo então da premissa de que apenas a redução da migração interna entre as atividades madeireira, da maçã e da batata não é suficiente para rompimento do ciclo vicioso do emprego em Palmas, e que o movimento Palmas Desenvolvida e o IFPR tem papéis fundamentais na condução do processo de mudança da matriz econômica local e promoção do desenvolvimento, apresentam-se a seguir algumas proposições de atividades que podem representar alternativas potenciais de efeitos propulsores fortes e/ou resgate de atividades econômicas estagnadas:

Produção de energia renovável: Está instalado hoje na cidade de Água Doce, vizinha a Palmas, um dos maiores parques de energia eólica do sul do país, gerando atualmente um volume de energia capaz de abastecer uma população de 500 mil habitantes, o equivalente a toda região sudoeste do Paraná. Há potencial natural para que novos parques eólicos se instalem na cidade vizinha de General Carneiro e mesmo nos campos de Palmas. Mas o que se sugere é ir além da exploração econômica do processo de montagem e instalação dos equipamentos, como é o caso da construção civil e o comércio, que usufruem da mão de obra volante 
destas montagens, mas o IFPR pode buscar parcerias no desenvolvimento de tecnologia dos equipamentos, área em que reside o maior valor agregado.

$A$ indústria de alimentos: a criação de bovinos é tradicional em Palmas; mais recentemente, ingressaram as produções de suínos e aves. Existe hoje uma agroindústria de processamento de carnes que, em termos mercadológicos, pode expandir as atividades, mas que necessita de infraestrutura, mão de obra qualificada e cadeia de suprimento de matéria-prima.

O turismo rural: apesar de não haver tradição na microrregião, apresenta excelente potencial, seja pela história, como o episódio da Guerra do Contestado, seja pela condição geográfica ou climática. Se comparada à região da serra catarinense, em especial as cidades de Lages e São Joaquim, onde esta atividade é extremamente evoluída e onde as condições naturais, históricas e culturais tem estreita similaridade com a condição de Palmas, existe um potencial importante a ser explorado.

O setor madeireiro: sugere-se o redirecionamento estratégico da indústria madeireira de Palmas, com alteração do portfólio de produtos, mudando gradativamente sua produção do compensado para o MDF (médium density fiberboard), material hoje largamente utilizado como matéria-prima da indústria nacional de móveis. De maior valor agregado que o compensado, o MDF utiliza, ainda, os mesmos recursos estratégicos que são a proximidade da matéria-prima (florestas de pinus) e o know how produtivo.

A fruticultura: o clima e a altitude de Palmas lhe conferem vantagens naturais na produção de algumas culturas, como é o caso da maçã e do mirtilo; no entanto, sugere-se que, além da produção e despacho dos produtos como matéria-prima a outras regiões, ocorra a industrialização destes produtos, agregando valor aos mesmos.

Além destas, existem outras atividades e potencialidades na cidade de Palmas e devem ser diagnosticadas, avaliadas e estimuladas, com objetivo de promover uma mudança estrutural da matriz econômica local. Como encaminhamento para efetivação destas atividades, apresenta-se a seguir, algumas ações de curto e longo prazo.

\section{Curto Prazo:}

- Pesquisa de mapeamento das cadeias produtivas de Palmas (parceria entre Palmas Desenvolvida e IFPR);

- Evento de aproximação entre o setor produtivo de Palmas e os pesquisadores do IFPR, proporcionando espaço para que o setor produtivo exponha suas necessidades especificas de pesquisa e desenvolvimento, e abrindo oportunidades para atuação dos pesquisadores da instituição (IFPR Coordenação de Pesquisa e Extensão); 
- Articulação de governança, especialmente das atividades econômicas potenciais acima propostas, permitindo organização do setor e construção de vantagens competitivas (IFPR - Eixo de Gestão e Negócios);

- Desenvolvimento de inteligência comercial e abertura de canais de comercialização aos produtos regionais (IFPR - Eixo de Gestão e Negócios e Governanças Setoriais).

\section{Longo Prazo:}

- Pesquisas aplicadas ao setor produtivo, desenvolvendo soluções de otimização dos processos produtivos e desenvolvimento de novos produtos (IFPR);

- Desenvolvimento e promoção da marca Palmas, seja institucionalmente, seja dos produtos regionais (IFPR e Palmas Desenvolvida);

- Desenvolvimento do planejamento estratégico de Palmas para 2030 (Palmas Desenvolvida).

Essas ações, a serem conduzidas pelo movimento Palmas Desenvolvida e pelo IFPR, representam oportunidades de promoção do desenvolvimento na cidade de Palmas, a partir de proposições de estratégias endógenas, coordenadas pelos atores locais, baseadas nas literaturas sobre o temática desenvolvimento local, como Ferrera de Lima (2011), Haddad (2009), Martinelli e Joyal (2004), Oliveira (2006), Vitte (2006) e Myrdal (1959).

\section{Conclusões}

Esse estudo teve como objetivo realizar um diagnóstico da dinâmica do emprego na cidade de Palmas-PR, como perspectiva de avaliação da condição do desenvolvimento local, a fim de detectar situações que pudessem indicar deficiências e propor alternativas de mudança. A revisão teórica procurou explicitar alguns conceitos de desenvolvimento, especialmente o desenvolvimento endógeno, a partir dos atores locais.

O diagnostico apresentou inicialmente uma caracterização do município de Palmas em termos históricos e quanto a sua estruturação econômica. Posteriormente, avaliou-se especificamente a questão da dinâmica do emprego, chegando-se a conclusão de que existe um problema de alta rotatividade do emprego no setor industrial, com movimento migratório para as atividades sazonais da colheita da maçã e da batata ou para o beneficio do seguro desemprego. Essa mesma mão de obra, ao término das colheitas temporárias ou o fim do beneficio de seguro desemprego, retorna para a indústria, fechando e, ao mesmo tempo, reiniciando este ciclo vicioso. 
Este ciclo é comparado ao ciclo vicioso da causação circular cumulativa apresentado por Myrdal, teoria pela qual também apresentam-se sugestões para a sua interrupção e sua conversão em circulo virtuoso, especialmente através do desenvolvimento de planejamento articulado e da aplicação de pesquisas. Para o planejamento articulado, propõe-se que seja conduzido pelo movimento Palmas Desenvolvida, que já esta em curso e para o qual os resultados do diagnostico deste trabalho podem servir como informações importantes. Para a pesquisa, a proposta é que seja conduzida pelo IFPR, articulando-a a extensão e ao ensino, e promovendo e estimulando o surgimento de novas atividades propulsoras no município.

Algumas destas atividades são propostas neste trabalho, como a manutenção da indústria madeireira, mas migrando o seu produto principal do compensado para o MDF. O mesmo para a fruticultura, mas procurando adicionar valor ao produto através do beneficiamento e industrialização. Outras atividades ainda incipientes ou inexistentes são propostas, como a produção de energia renovável, a indústria de alimentos e o turismo rural.

Para operacionalização dos estímulos às novas atividades econômicas ou à retomada das estagnadas, são propostas ações de curto prazo, como mapeamento das atividades produtivas, aproximação entre o IFPR e o setor produtivo, especialmente na área de pesquisa, e a organização das governanças destas atividades. Como atividades de longo prazo são sugeridos a condução de pesquisas aplicadas junto ao setor produtivo, seja no aprimoramento dos processos produtivos, seja no desenvolvimento de novos produtos, com a promoção de marcas regionais e também a elaboração do planejamento estratégico de Palmas para 2030. Estas ações estão de acordo com a proposta de Myrdal para rompimento do ciclo vicioso da causação circular cumulativa, através do planejamento integrado e da criação de políticas públicas, e da produção de conhecimento por pesquisas aplicadas as condições produtivas locais.

Como sugestões para trabalhos futuros, indica-se o aprofundamento do diagnóstico da dinâmica do emprego, através de pesquisa de campo e entrevistas com os empregados e empregadores, para que se compreenda com maiores detalhes as causas da alta rotatividade e da migração setorial que culminam no ciclo vicioso.

\section{Referências}

AGÊNCIA do Trabalhador/SETS de Palmas. Relatório de movimentação de benefícios de seguro desemprego, 2010, 2011, 2012 e 2013. Palmas, 2014. 
AMARAL FILHO, J. A endogeneização no desenvolvimento econômico regional e local. Planejamento e Políticas Públicas, Brasília, n. 23, p. 261-286, 2001.

BACEN. Banco Central do Brasil. Câmbio e capitais internacionais. Disponível em: http://www.bcb.gov.br/?CAMBIO. Acesso em: 22 nov. 2014.

BARDIN, Laurence. Análise de Conteúdo. Paris: Presses Universitaires de France, 1977.

BOISIER, Sérgio. Desarrollo (local): ¿de qué estamos hablando? In: BECKER, Dinizar; BANDEIRA, Pedro S. (Orgs.) Desenvolvimento Local - Regional: determinantes e desafios contemporâneos. Santa Cruz do Sul: EDUNISC, 2002.

CAGED. Cadastro Geral de Empregados e Desempregados. Perfil do Município. Disponível em: http://bi.mte.gov.br/bgcaged/caged perfil municipio/ index.php. Acesso em: 22 nov. 2014.

DENUZI, V. S. S.; FERRERA DE LIMA, J. Organizações e Desenvolvimento Local: o papel dos atores locais nos municípios de Assis Chateaubriand e PalotinaPR. Revista Ciências Sociais em Perspectiva, vol. 12, n. 23, 2. semestre, 2013.

FERRERA DE LIMA, J. Notas sobre os territórios na análise geoeconômica. Publicatio UEPG, Ciências Sociais Aplicadas, vol. 19, p. 47-54, 2011.

FRANCO, Augusto de. Além da renda: a pobreza brasileira como insuficiência de desenvolvimento. Brasília: Compukromus, 1999.

GREMAUD, A.; VASCONCELLOS, M. A. S. de; TONETO, R. Jr. Economia Brasileira Contemporânea. São Paulo: Atlas, 2002.

HADDAD, P. Capitais intangíveis e desenvolvimento regional. Revista de Economia, Curitiba, vol. 3, n. 3, p. 119-146, 2009.

HARROD, Roy Forbes. La teoría dinámica. In: SEN, Amartya (Org.). Economía del crescimiento. México: Fondo de Cultura Económica, 1979.

IBGE. Instituto Brasileiro de Geografia e Estatística. Perfil do município. Disponível em: http://www.cidades.ibge.gov.br/xtras/perfil.php?lang=\& codmun=411760\&search=parana $\mid$ palmas. Acesso em: 22 nov. 2014.

IPARDES. Caderno estatístico: município de Palmas. 2014. Disponível em: http://www.ipardes.gov.br/cadernos/MontaCadPdf1.php?Municipio=84670\&bt $\underline{\mathrm{Ok}=\mathrm{ok}}$. Acesso em: 25 nov. 2014. 
KALDOR, Nicholas. Un modelo de distribución. In: SEN, Amartya (Org.). Economía del crecimiento. México: Fondo de Cultura Económica, 1979.

KRÜGER, Nivaldo. Palmas: paisagem e memória. Palmas: Costábile Romano, 2002.

MARCONI, M. A.; LAKATOS, E. M. Fundamentos de metodologia científica. 7. ed. São Paulo: Atlas, 2010.

MARTINELLI, D. P. JOYAL A. Desenvolvimento local e o papel das pequenas e médias empresas. Barueri: Manoele, 2004.

MYRDAL, Gunnar. Teoría económica y regiones subdesarrolladas. México: Fondo de cultura económica: 1959.

OLIVEIRA, L. V. N.; FERRERA DE LIMA, J. O processo de construção da Política Nacional Desenvolvimento Regional no Brasil. Revista Portuguesa de Estudos Regionais, v. 31, p. 130-150, 2012.

OLIVEIRA, M. D. de. O desenvolvimento a partir da comunidade: do poço sem fundo das necessidades a valorização das capacidades. In: CARDOSO, R. et al. Sociedade civil, democracia e desenvolvimento: ideias e experiências em debate. São Paulo: Comunitas, 2006.

SCHLEMPER, Alexandre L. A relação da política pública de implantação do Instituto Federal do Paraná, Câmpus Palmas, com os Arranjos Produtivos Locais. In: II SEDRES - Seminário de Desenvolvimento Regional, Estado e Sociedade: A diversidade regional brasileira em perspectiva. Anais... Campina Grande, 13 a 15 de agosto, 2014.

SCHUMPETER, Joseph. Teoria do desenvolvimento econômico: uma investigação sobre lucros, capitais, crédito, juro e ciclo econômico. São Paulo: Abril Cultural, 1982.

SOLOW, Robert Merton. Progreso técnico y cambio de la productividad. In: SEN, Amartya (Org.). Economía del crecimiento. México: Fondo de Cultura Económica, 1979.

VITTE, C. de C. S. Gestão do desenvolvimento econômico local: algumas considerações. Revista Internacional de Desenvolvimento Local, vol. 8, n. 13, p. 77-87, 2006. 
Endereço para correspondência:

Alexandre Luiz Schlemper-alexandre.schlemper@ifpr.edu.br Av. Bento Munhoz da Rocha Neto, s/nº, PR-280

85.555-000 Palmas/PR, Brasil

178 | Revista Brasileira de Desenvolvimento Regional, Blumenau, 3 (1), P. 157-178, outono de 2015 